The Journal of Experimental Biology 216, 2165-2171 (c) 2013. Published by The Company of Biologists Ltd doi:10.1242/jeb.070250

\title{
COMMENTARY
}

\section{Forty years of olfactory navigation in birds}

\author{
Anna Gagliardo \\ Department of Biology, University of Pisa, Via A. Volta 6, I-56126 Pisa, Italy \\ agagliardo@biologia.unipi.it
}

\begin{abstract}
Summary
Forty years ago, Papi and colleagues discovered that anosmic pigeons cannot find their way home when released at unfamiliar locations. They explained this phenomenon by developing the olfactory navigation hypothesis: pigeons at the home loft learn the odours carried by the winds in association with wind direction; once at the release site, they determine the direction of displacement on the basis of the odours perceived locally and orient homeward. In addition to the old classical experiments, new GPS tracking data and observations on the activation of the olfactory system in displaced pigeons have provided further evidence for the specific role of olfactory cues in pigeon navigation. Although it is not known which odours the birds might rely on for navigation, it has been shown that volatile organic compounds in the atmosphere are distributed as fairly stable gradients to allow environmental odour-based navigation. The investigation of the potential role of olfactory cues for navigation in wild birds is still at an early stage; however, the evidence collected so far suggests that olfactory navigation might be a widespread mechanism in avian species.
\end{abstract}

Key words: avian, navigation, olfaction.

Received 1 October 2012; Accepted 6 March 2013

\section{Introduction}

Migratory birds routinely travel thousands of kilometres between their wintering grounds and reproductive areas, generally showing a high degree of fidelity to both their migratory route and their nesting site. Their performance cannot be explained without assuming that, along with an innate tendency to fly in a specific migratory direction determined by means of compass mechanisms, they possess the ability to establish their current position with respect to the current goal during the entire migratory flight. As shown by Perdeck (Perdeck, 1958) in displaced migrating starlings, adult birds were able to correct for their displacement, while juveniles on their first flight maintained their innate migratory direction, failing to demonstrate true navigational ability.

Although homing pigeons do not migrate, they have been selected by humans for their motivation and ability to home even when transported to non-familiar locations. Because of these behavioural traits they became a model species for the study of the mechanisms underlying navigation. A particularly relevant issue in the study of bird navigation is the nature of the environmental information providing the birds with positional information [the 'map step', according to Kramer's 'map and compass concept' (Kramer, 1953)]. Although there is general agreement that birds determine a direction in space ('compass step') and maintain it during flight by means of a time-compensated sun compass, and a magnetic compass that is mainly used when the sun is not visible, the sensory basis of the navigational map has been the subject of extensive research, which has generated a lively debate for about 70 years.

Different from other hypotheses on the nature of the cues involved in bird navigation (i.e. Coriolis force, sun altitude, components of the geomagnetic field, infrasounds), the olfactory navigation hypothesis was formulated to explain experimental findings, rather than being proposed on the basis of theoretical speculations. These findings were unexpected and were received with a certain degree of scepticism.

\section{A brief history}

About 40 years ago a simple experiment conducted in Tuscany changed the course of research on bird navigation: a group of pigeons with their olfactory nerves sectioned were released at an unfamiliar site and never returned; their intact companions rapidly flew back to the loft (Papi et al., 1971). At that time the olfactory sense was considered marginal in birds and olfactory cues had never been seriously taken into account among the possible sources of environmental information potentially useful for a position-finding mechanism. For this reason it might seem quite odd that a test release with anosmic pigeons was even conceived. Floriano Papi thought of testing the navigational abilities of anosmic homing pigeons because this sense was the only one (along with taste) not yet tested as potentially important in navigation. However, an important piece of information eventually prompted the first homing experiment with anosmic birds. At about the same time, Wallraff and colleagues were investigating the behaviour of pigeons raised in confined aviaries and exposed to different environmental stimuli. Their research aimed at testing whether a view of the horizon was critical for the pigeons to develop unimpaired navigational ability. Testing birds raised confined in an aviary provided with glass screens and birds raised in an aviary surrounded by a palisade, which prevented the full view of the horizon, they expected to observe an impairment only in the latter group. The results were clearly against expectations: the pigeons allowed to view the horizon, but sheltered from the winds by glass screens, were unable to orient towards home. By contrast, birds exposed to the winds passing through the palisade were unimpaired, even if the view of the surroundings was 
obstructed. These first results, later confirmed by subsequent experiments, led to the hypothesis that an 'atmospheric factor' was likely to be involved in navigation (Wallraff, 1970). In light of these results, testing the navigational abilities of anosmic pigeons did not appear odd. Both the results of Wallraff and Papi are explained by the 'olfactory navigation hypothesis' proposed by Papi (Papi et al., 1972): pigeons at their home area are able to learn windborne environmental odours in association with wind direction; once at the release site they are able to recognise the prevalent local odours and recall from which direction these odours come from at the home area in order to determine the direction of displacement (Fig. 1).

The evidence that local release site odours constitute a source of navigational information for homing pigeons has been demonstrated in an elegant experiment by Benvenuti and Wallraff (Benvenuti and Wallraff, 1985), in which the birds were fooled concerning the release site olfactory information. Pigeons were transported in airtight containers ventilated by air purified by charcoal filters to a false release site where they were allowed to breath local environmental air for a few hours. Then the birds were transported in pure air to a new site located in the opposite direction with respect to home, subjected to nasal anaesthesia and released. At the false release site these birds had experienced the local odours, while at the true release site this kind of information was not accessible. The birds oriented towards the 'false home direction', i.e. the home direction from the false release site, while the control birds exposed to the local air at the true release site oriented towards home.

\section{Anosmia specifically impairs pigeon navigation}

The first concern of the proponents of the olfactory navigation hypothesis was to exclude potential non-specific effects of nerve section and anosmia on pigeon behaviour (Papi et al., 1972). Importantly, it became clear soon that anosmic pigeons released at familiar locations orient and home as well as intact birds (Benvenuti et al., 1973). Since this early discovery, a large body of evidence collected with both traditional methods and GPS tracking has shown that, within a familiar area, pigeons navigate by relying on landscape features memorised during their previous homing flights (Biro et al., 2004; Holland, 2003). At familiar sites, intact pigeons rely on both an olfactory map and knowledge of familiar, visual topographical features, as shown by Gagliardo and colleagues (Gagliardo et al., 2001b). Exploiting the ability of birds to display homeward orientation in a cage at a release site, the orientation before take-off from a circular arena was recorded for both anosmic and intact pigeons displaced at familiar sites. The birds were tested twice from each of the three sites, but in one case the birds could view the surroundings, while in the other the arena was surrounded by a screen to prevent visual recognition of the place. While the intact pigeons displayed homeward orientation in both visual conditions, the anosmic birds headed homeward only when the view of the landscape was allowed.

The non-specific effect of the treatment can be excluded also on the basis of experiments in which unilateral nostril occlusion was combined with unilateral treatments for inducing anosmia (olfactory nerve section or washing the olfactory mucosa with zinc sulphate solution, which makes the olfactory neurons degenerate). It consistently emerged that only when the plug was placed contralaterally to the sectioned nerve/zinc-sulphate treated mucosa was the birds' homing performance dramatically impaired (Benvenuti and Gagliardo, 1996; Papi et al., 1972).

More recently, the side effect issue was raised again by Mora and colleagues in a paper reporting that pigeons trained to discriminate between the presence and absence of a strong magnetic field lost their magnetic discrimination abilities following section of the ophthalmic branch of the trigeminal nerve (Mora et al., 2004). The findings were consistent with other studies suggesting that the ophthalmic branch of the trigeminal nerve innervates magnetite-containing cells in the pigeons' upper beak and carry geomagnetic intensity information to the brain (Falkenberg et al., 2010). Mora and colleagues (Mora et al., 2004) argued that the navigational impairment of olfactory-manipulated pigeons might have been produced by accidental damage to the
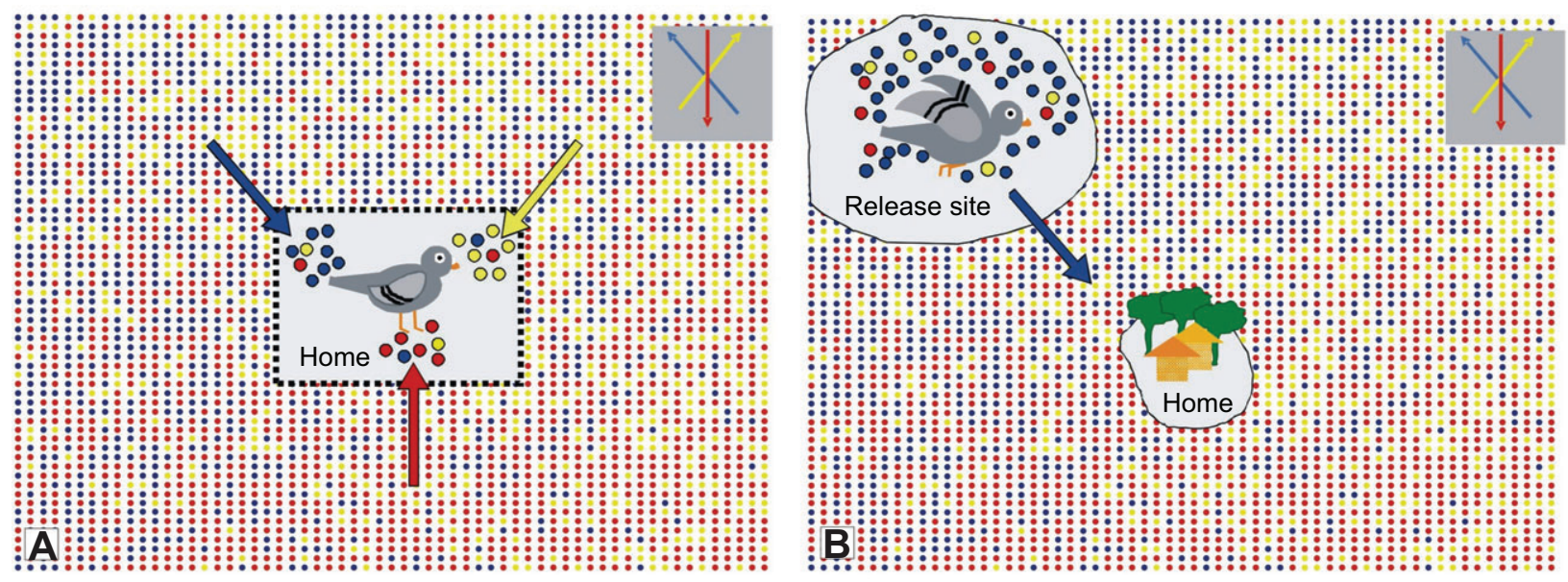

Fig. 1. Sketch of the olfactory navigation hypothesis according to Wallraff's idea that atmospheric odours are distributed along gradients (see 'The structure

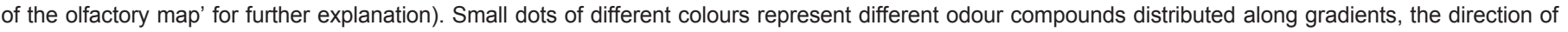
which are indicated by the arrows on the inset drawings. For simplicity, only three odours are represented. (A) Learning phase: at home birds learn windborne odours in association with wind direction. A pigeon inside an aviary open to the winds is represented for simplicity. However, this model is valid also for free-flying birds. (B) Operant phase: at the release site the bird gathers information about local odours; the more abundant presence of the 'blue' odour in comparison to the other two odours indicates that the bird has been displaced northwest. In fact, the bird has learned that the northwest wind was richer in 'blue' odour compounds. The bird orients southeast to fly home. The graphical representation is also consistent with the early view of Papi's 'mosaic map', if one assumes that different ratios of different compounds give a unique bouquet so that different areas are characterised by different smells. 
putative trigeminal magnetoreceptor in the upper beak. Actually, this assumption was already contradicted by previous evidence: birds subjected to anaesthesia of the nostrils prior to release were impaired if they were both transported and kept in pure air at the release location, but were unimpaired if they were exposed to environmental odours both during transportation and at the release site (Wallraff and Foà, 1981). By contrast, birds with the upper beak intact, but subjected to lesions of the piriform cortex, the telecephalic major projection field of the olfactory bulbs, were dramatically impaired in navigation from unfamiliar sites (Papi and Casini, 1990). It is worth noting that non-olfactory telencephalic lesions do not produce a total disruption of pigeons' navigational performance (Bingman et al., 1984). Because these findings were neglected, it was crucial to test simultaneously the possible involvement of the ophthalmic branch of trigeminal nerve and olfactory nerves in pigeon navigation. Together with Martin Wild, who had performed the nerve section in the magnetic conditioning experiment (Mora et al., 2004), we examined the effects of trigeminal nerve section on pigeon homing. Release experiments with naïve pigeons subjected to section of the ophthalmic branch of the trigeminal nerve demonstrated that this nerve is neither necessary nor sufficient for navigation: trigeminal-sectioned pigeons behaved the same as unmanipulated control birds. By contrast, olfactory-nerve-sectioned pigeons were impaired at homing despite having intact trigeminal nerves (Gagliardo et al., 2006). Interestingly, the results were the same regardless of the experience of the pigeons at the time of the surgery. Pigeons made anosmic when young and intensively trained turned out to be unable to learn a navigational map exploiting any alternative environmental information, while young birds subjected to trigeminal section developed unimpaired navigational abilities (Gagliardo et al., 2008). Consistent results were obtained also when the nerve section was performed on adult birds that had experienced the magnetic gradient of the area during their training flights (Gagliardo et al., 2009). More recently, it has been convincingly demonstrated that the upper beak cells containing ferromagnetic particles are macrophages, and do not constitute a magnetoreceptor (Treiber et al., 2012).

The involvement of the olfactory system in pigeon navigation has not been exclusively demonstrated by lesion experiments. In fact, the activation of the piriform cortex during navigational tasks from unfamiliar locations has been highlighted by comparing immediate early gene (ZENK) expression (Patzke et al., 2010) in the brain of three groups of pigeons: birds released at a non-familiar site, birds transported and kept at the same site but not released, and birds released in the vicinity of the loft. The highest number of ZENK-marked cells occurred in the piriform cortex of pigeons released at the unfamiliar location, and a significant number of marked cells were counted in the birds kept at the release site without being released. No activation of the piriform cortex was observed in the birds released in the home area, where birds exclusively rely on familiar visual cues to locate the loft (Gagliardo et al., 2007). These results are consistent with behavioural data showing that processing olfactory information is critical for both successful homing and homeward orientation in a cage prior takeoff (Gagliardo et al., 2001b).

\section{Anosmic pigeons do not home regardless of tester and test location}

Forty years of experiments conducted in different countries by different people have demonstrated that birds deprived of their sense of smell with a reliable long-lasting method and released at unfamiliar locations are, in most cases, randomly scattered or oriented in a direction different from the home direction, but always consistently impaired in their ability to find their way home [see Wallraff (Wallraff, 2005a) for references].

It is unknown which odours are preferentially learned by the pigeons in association with wind direction. Although it might be possible that any windborne odour might be incorporated in the map mechanism, it is reasonable to assume that biogenic odours are the most likely candidate. The latter are likely to change with the season, at least in temperate zones of the Earth, and in their availability and distribution according to the geophysical and ecological characteristics of an area. Interestingly, it has been observed that orientation and homing performance of pigeons belonging to the same colony varied according to season, as the birds performed better in spring-summer than autumn-winter (Foà et al., 1984). Many experiments conducted in different countries tested whether the nature of the cues used for navigation was different depending on the geographical region the birds were raised (Benvenuti et al., 1998; Benvenuti and Ranvaud 2004; Gagliardo et al., 2000). These experiments were stimulated by the idea that pigeons have a multi-cue system, and the nature of the cues preferentially used for navigation might depend on the availability of stimuli of a certain kind during map learning (Walcott, 1996). According to this, in environments or in experimental conditions characterised by poor environmental olfactory information, birds would develop a map based on magnetic cues. This idea is actually contradicted by the fact that olfactory-deprived young pigeons are unable to develop navigational abilities, even if subjected to an intensive program of training homing flights in a group with intact controls (Gagliardo et al., 1997; Gagliardo et al., 2008; Papi et al., 1989). In addition, navigational tests conducted in different countries showed that anosmic pigeons were impaired in every geographical area tested, but interestingly, the performance of the control pigeons varied considerably across different countries (Benvenuti et al., 1998), and were better in the Mediterranean, which is likely to be characterised by an environment richer in natural odours than elsewhere due to its high biodiversity of plant species (Myers et al., 2000).

If pigeons were endowed with a multi-cue navigational system composed of acoustic, olfactory and magnetic cues, it would be impossible to impair their navigational performance at unfamiliar locations by disrupting only one sensory system or by manipulating only one type of information. Considering all the evidence accumulated over 40 years, visual familiarity with the release site area turned out to be the only alternative source of information allowing navigation in olfactory-deprived pigeons.

\section{Manipulations of wind direction and windborne odours produced expected orientation in smelling birds}

Obviously, experiments involving manipulation of the olfactory system are not sufficient alone to provide a convincing support of olfactory navigation. For this reason, studying the orientation of intact birds exposed to manipulated environments was particularly revealing. Test releases on birds raised in screened aviaries (Gagliardo et al., 2001a; Wallraff, 1970) have clearly demonstrated that if the development of navigational abilities is prevented the birds cannot learn the association between wind direction and windborne odours.

In addition, the manipulation of the wind direction resulted in a predicted deflection of the initial orientation of the birds after release. Pigeons housed in aviaries provided with clockwise or counter-clockwise deflectors, once released, displayed a 
corresponding deflection in initial orientation (Baldaccini et al., 1975). This finding was consistently replicated by other authors (Phillips and Waldvogel, 1982); however, Phillips and Waldvogel proposed an alternative explanation to the phenomenon. According to their view, the deflectors might have deflected also polarized light, and therefore the deviation in initial orientation was interpreted as a rotation of the sun compass rather than rotation of the olfactory map. It is worth noting that the ability to perceive polarized light by homing pigeons is controversial (Hzn et al., 1995). However, another kind of wind manipulation produced results not explicable by deflection of polarized light. In the latter, pigeons were housed in corridor cages provided with large fans at both ends (Ioalè et al., 1978; Ioalé, 1980). For the experimental pigeons, each fan automatically switched on when the wind was blowing from the opposite direction, so as to produce an inversion of the wind direction inside the cage. The control birds were housed in an identical cage, but this time the fans switched on so as to leave the natural direction of the winds unaltered. Once released, the control birds headed home, while the experimental group headed in the direction opposite to home.

One of the most convincing pieces of evidence in favour of olfactory navigation is that pigeons can incorporate artificial odours in their olfactory map if exposed to artificial air currents blowing artificial odours from specific directions (Ioalè et al., 1990; Papi et al., 1974). In one experiment (Fig. 2), a group of birds received turpentine from the north and olive oil from the south, while for another group of pigeons turpentine was blown from south and olive oil from north. The birds were then displaced east and exposed to one of the two odours at the release site. When exposed to turpentine prior to release, the birds that had learned that turpentine was associated with the north wind oriented southward, while the group that had learned that turpentine was associated with the south wind headed north. Complementary results were achieved by stimulating the pigeons with olive oil. Therefore, one group of birds learned that northern areas were rich in turpentine and the southern areas were rich in olive oil; for the other group of pigeons this map was turned $180 \mathrm{deg}$.

Interestingly, stimulation with artificial odours produced initial orientation towards an expected direction only if the birds had been previously exposed to these odours in association with a wind direction at the home loft. In fact, artificial nonsense odours presented to the birds at the release site only acted as disturbing factors (Benvenuti et al., 1977), probably because they prevented a clear perception of the local environmental odours.

The experiments described above support a specific role of environmental odours in pigeon navigation and contradict the olfactory activation hypothesis ante litteram, predicting that smells only function to trigger a navigational mechanism based on non-
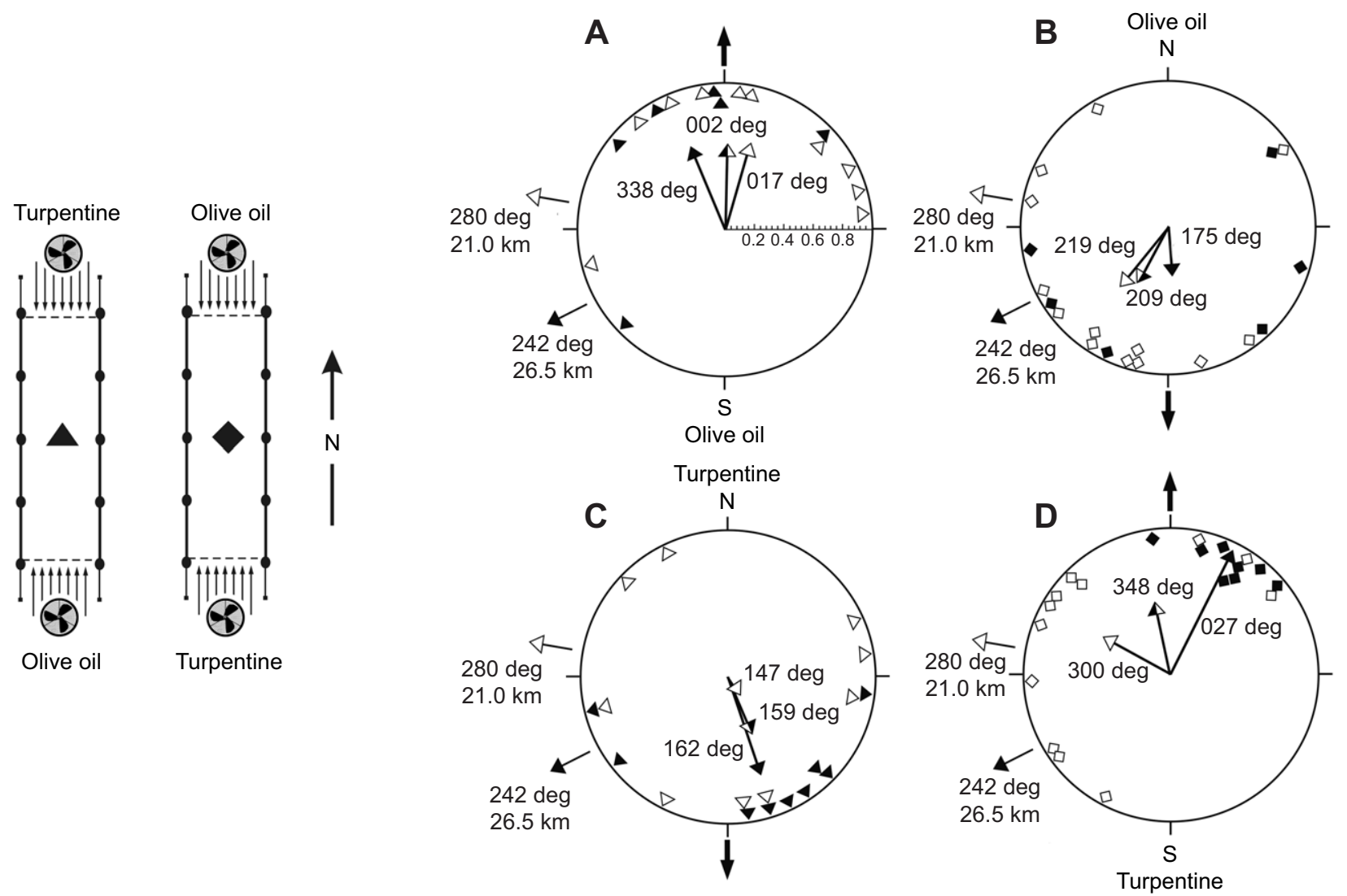

Fig. 2. Orientation of pigeons exposed to odorous air currents. The birds were kept in a corridor-like aviary and exposed for some hours per day to odorous air current. Only one odour was delivered at a time. One group of birds (triangles) was exposed to olive oil from the south and turpentine from the north; another group of birds (diamonds) was exposed to olive oil from the north and turpentine from the south. The circular diagrams report the initial orientation of the birds when released from two sites (home direction and distance are indicated near the small outer arrows). Before being released the birds were exposed to one of the two odours (olive oil, A and B; turpentine, C and D) learned in association with the artificial wind direction and oriented consistently to the expected direction (large outer arrow) predicted by the artificial odour current. The mean vectors of the initial orientation distributions are represented by the inner arrows (filled, open and half-filled/open symbols refer to the two different release sites and to the pooled distribution, respectively). The mean vector lengths can be read on the scale in A. Data are from Papi et al. (Papi et al., 1974). 
olfactory cues (either magnetic or acoustic) and cannot constitute a source of positional information (Jorge et al., 2009). Jorge and colleagues reported vanishing bearing data showing that birds deprived of environmental olfactory information, but exposed to artificial nonsense odours, were unimpaired in their initial orientation. A recent experiment has provided evidence against the activational role of olfactory stimuli (Gagliardo et al., 2011): the birds were subjected to the same olfactory manipulation as in Jorge et al. (Jorge et al., 2009), but their performance was better documented thanks to remotely downloadable GPS data loggers such that the tracks of non-homed birds could be recorded. Pigeons deprived of environmental olfactory information, although exposed to artificial nonsense odours, displayed tortuous tracks, poor homeward orientation and the tendency to remain around the release site area.

The olfactory activation hypothesis, besides being contradicted by experimental evidence, is also not the most simple explanation for the navigational impairment following anosmia. Considering the fact that magnetic manipulation [see references in Walcott (Walcott, 1991) and Wallraff (Wallraff, 2005a)] or acoustic deprivation (Wallraff, 1972) do not disrupt pigeon homing abilities, the validity of the olfactory activation hypothesis implies an unlikely picture: disruption of navigational performance is never obtained by direct manipulation of the sensory cues composing the navigational map (magnetic and/or acoustic), but only by depriving the birds of a kind of stimuli (olfactory) not involved in the map mechanism.

\section{The structure of the olfactory map}

The olfactory map hypothesis conceptually is a mechanism used in the 'map step' described by Kramer to indicate the phase during which a displaced bird establishes its position with respect to the goal (Kramer, 1953). However, the odour-based map does not have the structure of a map defined by a bicoordinate system, thereby giving the exact position and distance of two points with respect to each other. The olfactory map is supposed to provide information exclusively about the direction of displacement. For this reason, once arrived in the home area, homing pigeons need to rely on cues of another nature to localise the home loft (Wallraff, 2005b). The important role of familiar visual landmarks learned during spontaneous flights around the loft has been recently demonstrated by a GPS experiment (Gagliardo et al., 2007). Displaced pigeons raised confined in an aviary open to the winds were able to orient towards home and to approach the home area. However, their limited experience of the surroundings during their stay at the home aviary resulted in a greater difficulty in recognising the home area and localising their colony.

Papi had imagined that environmental odours might have a patchy distribution, which would thus constitute a mosaic map (Papi et al., 1972). One could hardly imagine that such a mechanism would allow navigation from sites more than $100 \mathrm{~km}$ distant unless the birds could memorise the odours characterising the areas crossed during transportation to the release site. A series of experiments showed that odours perceived during transportation indeed constituted a source of positional information (Papi et al., 1973; Wallraff and Foà, 1981).

One of the most important criticisms of the olfactory map hypothesis was that it seemed unlikely that atmospheric odours could have a stable spatial distribution to provide reliable spatial information (Waldvogel, 1987). Hans Wallraff addressed this question and proposed an alternative model explaining how birds might derive their position with respect to the goal on the basis of environmental odour distribution. Wallraff and Andreae (Wallraff and Andreae, 2000) collected samples of air from 96 sites regularly distributed within $200 \mathrm{~km}$ around a loft of pigeons tested in many displacement experiments in Germany. The gas chromatography of these samples of air identified a number of volatile organic compounds and revealed that they are distributed along fairly stable spatial gradients in the atmosphere. With a simulation experiment, Wallraff showed that stable ratios, rather than the absolute concentrations, of at least three different volatile compounds are sufficient to provide suitable information to allow virtual pigeons to display a level of homeward orientation comparable to that experimentally observed (Wallraff, 2000). It is worth noting that such a model would theoretically allow also long-distance navigation well beyond a few hundred kilometres.

\section{Olfactory navigation in wild species}

Although olfactory navigation was discovered in homing pigeons, it is reasonable to assume that the use of environmental odours in navigation might be widespread in birds. Wallraff has extensively discussed this point, suggesting that olfactory cues might be used by birds not only for homing to their breeding colony or to their nest, but also during migration to correct for possible drift (Wallraff, 2005a). Among birds, Procellariformes have been often suggested as a good candidate for the use of smell in navigation (Bonadonna et al., 2003; Wallraff and Andreae, 2000). In fact, these birds possess a particularly well-developed olfactory apparatus and have been shown to use odours to locate food in the ocean and to find their burrow in the colony area (Dell'Ariccia and Bonadonna, 2013; Nevitt, 2008).

So far, the investigation of a possible role of olfactory cues in wild bird navigation is still at an early stage. Apart from a couple of studies showing homing impairment in anosmic swifts (Apus apus) displaced from their colony in Italy (Fiaschi et al., 1974) and anosmic starlings (Sturnus vulgaris) displaced more than $100 \mathrm{~km}$ from their breeding site area in Bavaria (Wallraff et al., 1995), this subject has been neglected until very recently, when the sensory basis of navigation was tested in migrating catbirds (Holland et al., 2009). Both young and adult catbirds (Dumetella carolinensis) were caught during migration in Illinois and subjected to sensory manipulation before being displaced east to New Jersey. Some were subjected to a magnetic pulse, some were made anosmic with zinc-sulphate nasal washing, and some were unmanipulated. Before being released they were provided with mini-transmitters so that they could be tracked with the aid of an airplane. Similar to the Perdeck's starlings, the juvenile catbirds oriented south, regardless of the sensory manipulation they had received. The adult catbirds subjected to magnetic pulse behaved similar to the unmanipulated control birds and oriented westwards, while the anosmic adult catbirds oriented southward, similar to the juvenile birds that, being on their first flight, were still unable to navigate. This experiment provided the first evidence that olfactory cues are involved in wild bird navigation during migration.

\section{Open questions and perspectives}

After 40 years of intensive research, often stimulated by the understandable scepticism by opponents of the olfactory navigation hypothesis, a large body of compelling evidence, obtained with an incredible variety of methods, supports the specific role of olfactory cues in pigeon navigation over unfamiliar areas. The old resistance to accept that odours are important in bird biology disappeared and even advanced the idea that a primary function of olfaction in 
vertebrates might be navigation, i.e. predicting odorant distributions in time and space (Jacobs, 2012).

Nevertheless, the debate on olfactory navigation in birds is still going on, partly due to some resistance in abandoning the more entrenched, but poorly supported, idea that birds possess a magnetic-based position-finding mechanism. As magnetic manipulations do not affect birds' homing performance, the lack of direct experimental support for the existence of a magnetic map allowing pigeons to establish their current position with respect to home has been stressed in the past (Walcott, 1991; Wallraff, 2005a; Wiltschko and Wiltschko, 1996). Although recent field experiments failed to product direct evidence for a geomagneticbased position-finding mechanism in birds (e.g. Bonadonna et al., 2005) [see Wallraff (Wallraff, 2005a) for references], this fact is generally concealed or not sufficiently emphasised in recent papers on field intensity magnetoreception (Falkenberg et al., 2010; Treiber et al., 2012). As a consequence, general readers are likely to get the wrong idea that not only magnetic orientation, but also magnetic navigation, is a well-established phenomenon in birds.

Nowadays, the disruptive effect of anosmia on pigeons homing is acknowledged even by historical opponents of olfactory navigation (Jorge et al., 2010); however, these authors deny a specific role of environmental odours in navigation on the basis of unconfirmed findings and despite the evidence against this view [see Gagliardo (Gagliardo et al., 2011) for references].

The research on the role of olfaction in navigation is not over and important issues still deserve further investigation. Is olfactory navigation a widespread mechanism in birds (Fiaschi et al., 1974; Wallraff et al., 1995; Holland et al., 2009)? Does oceanic navigation performed by seabirds critically depend on olfactory cues? Are olfactory cues only used for homing to the nest, or are olfactory cues a key component of wild birds' navigation during migration, as suggested by the only tracking experiment on a migrating passerine published so far (Holland et al., 2009)? Do birds exploit any atmospheric signal, or rely on specific categories of chemical compounds? Do birds establish the direction of displacement on the basis of odour gradients (Wallraff and Andreae, 2000) or rely on patches of different odours (Papi et al., 1972)? The use of satellite telemetry coupled with sensory manipulation experiments in wild birds and the analysis of environmental data in relation to bird movements will hopefully provide new insights into bird navigation (Guilford et al., 2011).

\section{Glossary}

Anosmic

Deprived of the sense of smell.

\section{Compass}

A behavioural mechanism allowing the selection of a specific direction in space on the basis of an external reference, such as the sun azimuth and the geomagnetic field.

Macrophage

A cell of the immune system.

\section{Navigational map}

A behavioural mechanism allowing a subject to establish the current position with respect to the goal on the basis of environmental cues.

\section{Piriform cortex}

The region of the brain, more precisely of the telencephalon, that receives direct input from the olfactory bulb. The piriform cortex is involved in the discrimination and memorization of odour stimuli.

Trigeminal nerve

The fifth cranial nerve. It has three branches, with sensory (the ophthalmic nerve and the maxillary nerve) or sensory-motor (the mandibular nerve) functions.
True navigation

The ability of a subject to reach a goal by calculating the goal position on the basis of local cues [the 'map step', according to Kramer's definition (Kramer, 1953)] and by determining the goal direction in space (the 'compass step', according to Kramer's definition).

Vanishing bearing

The direction of a released bird when vanishing from the observer's view at the release site.

ZENK

An immediate early gene rapidly expressed in response to external stimuli. An increased expression of the ZENK protein in certain brain regions can be directly linked to neuronal activity.

\section{Acknowledgements}

I am grateful to Floriano Papi and Verner Bingman for their critical comments on the manuscript. I thank Francesca Odetti and Daniele Santerini for their help in preparing the figures.

No competing interests declared.

\section{Competing interests}

\section{Funding}

This research received no specific grant from any funding agency in the public, commercial, or not-for-profit sectors.

\section{References}

Baldaccini, N. E., Benvenuti, S., Fiaschi, V. and Papi, F. (1975). Pigeon navigation: effects of wind deflection at home cage on homing behaviour. J. Comp. Physiol. 99, 177-186.

Benvenuti, S. and Gagliardo, A. (1996). Homing behaviour of pigeons subjected to unilateral zinc sulphate treatment of their olfactory mucosa. J. Exp. Biol. 199, 25312535.

Benvenuti, S. and Ranvaud, R. D. (2004). Olfaction and the homing ability of pigeons raised in a tropical area in Brazil. J. Exp. Zool. A Comp. Exp. Biol. 301, 961-967.

Benvenuti, S. and Wallraff, H. G. (1985). Pigeon navigation: site simulation by means of atmospheric odours. J. Comp. Physiol. A 156, 737-746.

Benvenuti, S., Fiaschi, V., Fiore, L. and Papi, F. (1973). Homing performances of inexperienced and directionally trained pigeons subjected to olfactory nerve section. J. Comp. Physiol. 83, 81-92.

Benvenuti, S., Fiaschi, V. and Foà, A. (1977). Homing behaviour of pigeons disturbed by application of an olfactory stimulus. J. Comp. Physiol. A 120, 173-179.

Benvenuti, S., Bingman, V. P. and Gagliardo, A. (1998). Effect of zinc-sulphate induced anosmia on pigeon homing: a comparison among birds in different regions. Trends Comp. Biochem. Physiol. 5, 221-228.

Bingman, V. P., Bagnoli, P., loalè, P. and Casini, G. (1984). Homing behavior of pigeons after telencephalic ablations. Brain Behav. Evol. 24, 94-108.

Biro, D., Meade, J. and Guilford, T. (2004). Familiar route loyalty implies visual pilotage in the homing pigeon. Proc. Natl. Acad. Sci. USA 101, 17440-17443.

Bonadonna, F., Benhamou, S. and Jouventin, P. (2003). Orientation in 'featureless' environments: the extreme case of pelagic birds. In Avian Migration (ed. P. Berthold, E. Gwinner and E. Sonnenschein), pp. 367-377. Berlin/Heidelberg: Springer.

Bonadonna, F., Bajzak, C., Benhamou, S., Igloi, K., Jouventin, P., Lipp, H.-P. and Dell'Omo, G. (2005). Orientation in the wandering albatross: interfering with magnetic perception does not affect orientation performance. Proc. Biol. Sci. 272, 489-495.

Dell'Ariccia, G. and Bonadonna, F. (2013). Back home at night or out until morning? Nycthemeral variations in homing of anosmic Cory's shearwaters in a diurnal colony. J. Exp. Biol. 216, 1430-1433.

Falkenberg, G., Fleissner, G., Schuchardt, K., Kuehbacher, M., Thalau, P., Mouritsen, H., Heyers, D., Wellenreuther, G. and Fleissner, G. (2010). Avian magnetoreception: elaborate iron mineral containing dendrites in the upper beak seem to be a common feature of birds. PLOS ONE 5, e9231.

Fiaschi, V., Farina, M., and loalé, P. (1974). Homing experiments on swifts Apus apus (L.) deprived of olfactory perception. Monit. Zool. Ital. (N.S.) 8, 235-244.

Foà, A., Benvenuti, S., loalè, P. and Wallraff, H. G. (1984). Geographical and temporal variability in pigeon homing. Parallel studies in Italy and Germany. Behav. Ecol. Sociobiol. 15, 25-34.

Gagliardo, A., Mazzotto, M. and Bingman, V. P. (1997). Piriform cortex ablations block navigational map learning in homing pigeons. Behav. Brain Res. 86, 143-148.

Gagliardo, A., El Agbani, A. and Bingman, V. P. (2000). Olfaction and the navigational performance of homing pigeons on the Atlantic coast of Morocco. Ital. J. Zool. 67, 359-364.

Gagliardo, A., loalè, P., Odetti, F. and Bingman, V. P. (2001a). The ontogeny of the homing pigeon navigational map: evidence for a sensitive learning period. Proc. Biol. Sci. 268, 197-202.

Gagliardo, A., Odetti, F. and loalè, P. (2001b). Relevance of visual cues for orientation at familiar sites by homing pigeons: an experiment in a circular arena. Proc. Biol. Sci. 268, 2065-2070.

Gagliardo, A., loalè, P., Savini, M. and Wild, J. M. (2006). Having the nerve to home: trigeminal magnetoreceptor versus olfactory mediation of homing in pigeons. J. Exp. Biol. 209, 2888-2892. 
Gagliardo, A., loalè, P., Savini, M., Lipp, H.-P. and Dell'Omo, G. (2007). Finding home: the final step of the pigeons' homing process studied with a GPS data logger. J. Exp. Biol. 210, 1132-1138.

Gagliardo, A., loalè, P., Savini, M. and Wild, M. (2008). Navigational abilities of homing pigeons deprived of olfactory or trigeminally mediated magnetic information when young. J. Exp. Biol. 211, 2046-2051.

Gagliardo, A., loalè, P., Savini, M. and Wild, M. (2009). Navigational abilities of adult and experienced homing pigeons deprived of olfactory or trigeminally mediated magnetic information. J. Exp. Biol. 212, 3119-3124.

Gagliardo, A., loalè, P., Filannino, C. and Wikelski, M. (2011). Homing pigeons only navigate in air with intact environmental odours: a test of the olfactory activation hypothesis with GPS data loggers. PLoS ONE 6, e22385.

Guilford, T., Åkesson, S., Gagliardo, A., Holland, R. A., Mouritsen, H., Muheim, R., Wiltschko, R., Wiltschko, W. and Bingman, V. P. (2011). Migratory navigation in birds: new opportunities in an era of fast-developing tracking technology. J. Exp. Biol. 214, 3705-3712.

Holland, R. A. (2003). The role of visual landmarks in the avian familiar area map. J. Exp. Biol. 206, 1773-1778.

Holland, R. A., Thorup, K., Gagliardo, A., Bisson, I.-A., Knecht, E., Mizrahi, D. and Wikelski, M. (2009). Testing the role of sensory systems in the migratory heading of a songbird. J. Exp. Biol. 212, 4065-4071.

Hzn, J., Coemans, M. and Nuboer, J. (1995). No evidence for polarization sensitivity in the pigeon electroretinogram. J. Exp. Biol. 198, 325-335.

loalé, P. (1980). Further investigationson the homing behaviour of pigeons subjected to reverse wind direction at the loft. Monit. Zool. Ital. 14, 77-87.

loalè, P., Papi, F., Fiaschi, V. and Baldaccini, N. E. (1978). Pigeon navigation: effects upon homing behaviour by reversing wind direction at the loft. J. Comp. Physiol. 128, 285-295.

loalè, P., Nozzolini, M. and Papi, F. (1990). Homing pigeons do extract directional information from olfactory stimuli. Behav. Ecol. Sociobiol. 26, 301-305.

Jacobs, L. F. (2012). From chemotaxis to the cognitive map: the function of olfaction. Proc. Natl. Acad. Sci. USA 109 Suppl. 1, 10693-10700.

Jorge, P. E., Marques, P. A. and Phillips, J. B. (2010). Activational effects of odours on avian navigation. Proc. Biol. Sci. 277, 45-49.

Kramer, G. (1953). Wird die Sonnenhöhe bei der Heimfindeorientierung verwertet? J. Ornithol. 94, 201-219.

Mora, C. V., Davison, M., Wild, J. M. and Walker, M. M. (2004). Magnetoreception and its trigeminal mediation in the homing pigeon. Nature 432, 508-511.

Myers, N., Mittermeier, R. A., Mittermeier, C. G., da Fonseca, G. A. B. and Kent, J. (2000). Biodiversity hotspots for conservation priorities. Nature 403, 853-858.

Nevitt, G. A. (2008). Sensory ecology on the high seas: the odor world of the procellariiform seabirds. J. Exp. Biol. 211, 1706-1713.

Papi, F. and Casini, G. (1990). Pigeons with ablated pyriform cortex home from familiar but not from unfamiliar sites. Proc. Natl. Acad. Sci. USA 87, 3783-3787.

Papi, F., Fiore, L., Fiaschi, V., and Benvenuti, S. (1971). The influence of olfactory nerve section on the homing capacity of carrier pigeons. Monit. Zool. Ital. 5, 265-267.

Papi, F., Fiore, L., Fiaschi, V. and Benvenuti, S. (1972). Olfaction and homing in pigeons. Monit. Zool. Ital. 6, 85-95.
Papi, F., Fiaschi, V., Benvenuti, S., and Baldaccini, N. E. (1973). Pigeon homing: outward journey detours influence the initial orientation. Monit. Zool. Ital. 7, 129-133.

Papi, F., loalè, P., Fiaschi, V., Benvenuti, S. and Baldaccini, N. E. (1974). Olfactory navigation of pigeons: the effect of treatment with odorous air currents. J. Comp. Physiol. A 94, 187-193.

Papi, F., Gagliardo, A., Fiaschi, V. and Dall'Antonia, P. (1989). Pigeon homing: does early experience determine what cues are used to navigate? Ethology 82, 208215

Patzke, N., Manns, M., Güntürkün, O., loalè, P. and Gagliardo, A. (2010). Navigation-induced ZENK expression in the olfactory system of pigeons (Columba livia). Eur. J. Neurosci. 31, 2062-2072.

Perdeck, A. C. (1958). Two types of orientation in migrating starlings, Sturnus vulgaris L., and chaffinches, Fringilla coelebs L., as revealed by displacement experiments. Ardea 46, 1-37.

Phillips, J. B. and Waldvogel, J. A. (1982). Reflected light cues generate the shortterm deflector loft effect. In Avian Navigation (ed. F. Papi and H. G. Wallraff), pp. 190-202. Berlin: Springer-Verlag.

Treiber, C. D., Salzer, M. C., Riegler, J., Edelman, N., Sugar, C., Breuss, M., Pichler, P., Cadiou, H., Saunders, M., Lythgoe, M. et al. (2012). Clusters of ironrich cells in the upper beak of pigeons are macrophages not magnetosensitive neurons. Nature 484, 367-370.

Walcott, C. (1991). Magnetic map in pigeons. In Orientation in Birds (ed. P. Berthold), pp. 38-51. Basel: Birkhäuser Verlag.

Walcott, C. (1996). Pigeon homing: observations, experiments and confusions. J. Exp. Biol. 199, 21-27.

Waldvogel, J. A. (1987). Olfactory navigation in homing pigeons: are the current models athmospherically realistic? Auk 104, 369-379.

Wallraff, H. G. (1970). Weitere Volierenversuche mit Brieftauben: wahrscheinlicher Einfluss dynamischer Faktorender Atmosphare auf die Orientierung. Z. Vgl. Physiol. 68, 182-201.

Wallraff, H. G. (1972). Homing of pigeons after extirpation of their cochleae and lagenae. Nat. New Biol. 236, 223-224.

Wallraff, H. G. (2000). Simulated navigation based on observed gradients of atmospheric trace gases (Models on pigeon homing, Part 3). J. Theor. Biol. 205 , 133-145.

Wallraff, H. G. (2005a). Avian Navigation: Pigeon Homing as a Paradigm. Heidelberg: Springer-Verlag

Wallraff, H. G. (2005b). Beyond familiar landmarks and integrated routes: goaloriented navigation by birds. Connect. Sci. 17, 91-106.

Wallraff, H. G. and Andreae, M. O. (2000). Spatial gradients in ratios of atmospheric trace gases: a study stimulated by experiments on bird navigation. Tellus $B$ Chem. Phys. Meteorol. 52, 1138-1157.

Wallraff, H. G. and Foà, A. (1981). Pigeon navigation: charcoal filter removes relevant information from environmental air. Behav. Ecol. Sociobiol. 9, 67-77.

Wallraff, H. G., Kiepenheuer, J., Neumann, M. F. and Streng, A. (1995). Homing experiments with starlings deprived of the sense of smell. Condor 97, 20-26.

Wiltschko, W. and Wiltschko, R. (1996). Magnetic orientation in birds. J. Exp. Biol. 199, 29-38. 